\title{
Perplexity of penile rehabilitation following radical prostatectomy
}

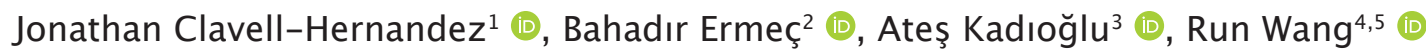

Cite this article as: Clavell-Hernandez J, Ermeç B, Kadığlu A, Wang R. Perplexity of penile rehabilitation following radical prostatectomy. Turk J Urol 2019; 45(2): 77-82.

ORCID IDs of the authors: J.CH. 0000-0001-5438-2217; B.E. 0000-0002-7680-9119; A.K. $0000-0002-4239-7638$; R.W. 0000-0002-6635-4093

${ }^{1}$ St Joseph Medical Center, Houston, Texas, USA ${ }^{2}$ Department of Urology İstinye State Hospital, İstanbul, Turkey ${ }^{3}$ Department of Urology, İstanbul University İstanbul School of Medicine, İstanbul, Turkey

${ }^{4}$ Department of Surgery, Division of Urology, University of Texas Health Science Center- McGovern Medical School at Houston, Houston, Texas, USA

${ }^{5}$ University of Texas MD Anderson Cancer Center, Houston, Texas, USA

Submitted:

03.10.2018

Accepted:

28.11.2018

Available Online Date: 22.01.2019

Corresponding Author: Run Wang

E-mail: run.wang@uth.tmc.edu

@Copyright 2019 by Turkish Association of Urology

Available online at www.turkishjournalofurology.com

\begin{abstract}
Radical prostatectomy has significantly improved prostate cancer survival rates but continues to have a negative impact on the patient's erectile function (EF). In attempts to improve erectile dysfunction (ED), clinicians have incorporated different treatment modalities to restore EF. Penile rehabilitation consists of understanding the mechanisms that affect post-prostatectomy EF and utilizing pharmacologic agents, devices, and interventions to promote the male sexual function. This article aims to summarize the available scientific research involving penile rehabilitation. Even though the current literature lacks to prove its irrefutable effectiveness, penile rehabilitation has a positive impact at the molecular and cellular levels, and it is widely adopted in clinic practices.
\end{abstract}

Keywords: Erectile function; penile rehabilitation; radical prostatectomy.

\section{Introduction}

Radical prostatectomy (RP) techniques have improved in the last few decades. The 5-year survival rates after treatment for prostate cancer are approximately $100 \%$ when localized to the prostate. ${ }^{[1]}$ Despite its efficacy in treating prostate cancer, it has been shown that RP has a pernicious effect on the patient's erectile function (EF) and urinary continence, and hence, the patient's quality of life and general well-being. ${ }^{[2,3]}$ Once robot-assisted surgery was introduced into the market, it was considered that this technology would refine nerve-sparing procedures through three-dimensional magnification and movement calibration, thereby improving postprostatectomy erectile dysfunction (ED) rates. [4,5] Haglind et al. ${ }^{[5]}$ prospectively compared the patient-reported outcomes of 2625 men with regard to urinary incontinence and ED 12 months after robotic-assisted laparoscopic prostatectomy (RALP) vs. retropubic RP (RRP). At 12 months, 366 (21.3\%) men reported urinary incontinence after RALP, and 144 (20.2\%) men after RRP (the adjusted OR was $1.08,95 \% \mathrm{CI}$, 0.87-1.34). ED, on the other hand, was noted to be statistically different in favor of RALP, with
$1200(70.4 \%)$ men reporting ED after RALP vs. $531(74.7 \%)$ men after RRP (OR 0.81, 95\% CI, 0.66-0.98). ${ }^{[5]}$ A meta-analysis of the studies reporting $\mathrm{EF}$ in patients with good erections prior to surgery demonstrated a range of potency rates after laparoscopic radical prostatectomy (LRP) vs. RRP vs. RALP at 48 months as 58\%$74 \%, 49 \%-74 \%$, and $60 \%-100 \%$, respectively. ${ }^{[6]}$

Overall, the incidence of ED after RP varies and has been reported to be between $14 \%$ and $90 \%$. ${ }^{[3,7-9]}$ Based on the available literature, it is not possible to accurately estimate the true incidence of ED after RP owing to the discrepancy among the series data. Salonia et al. ${ }^{[7]}$ reported a considerable variation in the nature of the populations studied, modality for data collection and reporting, and a formidable inconsistency in the rationale of what is considered a normal EF before and after RP. Tal et al. ${ }^{[10]}$ conducted a meta-analysis in which 22 different definitions of favorable EF outcomes were determined and it was concluded that most of the published literature does not meet the strict criteria involved in reporting EF recovery after RP. Therefore, an accurate interpretation of the incidence and prevalence of post-RP ED cannot be precisely calculated. 
Penile rehabilitation consists of understanding the mechanisms that lead to ED and utilizing different treatment modalities to promote the recovery of the male sexual function before and after any insult to the penile erectile physiological axis. ${ }^{[11]}$ In spite of learning and understanding the processes and rationales in penile rehabilitation after RP, there is still no consensus regarding the most effective rehabilitation program. This article aims to review the available evidence behind penile rehabilitation after RP.

\section{Pathophysiology of post-prostatectomy ED}

The pathophysiology of post-prostatectomy ED has been found to be multifactorial. There is evidence that suggests that changes in neuropraxia, ischemic and hypoxic insults, fibrotic remodeling, and apoptosis of cells contribute toward ED even after the neurovascular bundle is meticulously dissected during prostatectomy. ${ }^{[3]}$ The mechanical stretching of cavernous nerves during prostate retraction, thermal injury from electrocauterization, inflammation from surgical trauma, and nerve ischemia secondary to damage to the blood supply lead to neuropraxia. Studies have shown that even in the most cautious dissection procedures during nerve-sparing RP, neuropraxia can occur, and it may take up to three years for these nerves to fully recover. ${ }^{[12-14]}$

Research has proven that cavernous nerves are essential structures in providing normal EF. Several basic scientific studies have demonstrated that the numbers of proapoptotic and profibrotic factors increase in the cavernosal tissue after the nerves have been resected. ${ }^{[15]}$ Cavernous nerve damage during surgery decreases the amount of neuronal nitric oxide (nNOS) and nitric oxide (NO), which itself reduces penile rigidity and decreases the number of nocturnal erection episodes ${ }^{[16]}$ A study by Champion et al. ${ }^{[17]}$ involving animals showed that injury to the cavernosal nerve causes the penis to remain flaccid. Further, this causes cavernosal hypoxia that leads to decreased levels of prostaglandin E-1 (PGE-1), while increasing the local concentration of transforming growth factor $\beta$ (TGF- $\beta$ ) and endothelin 1 (ET-1). Together, PGE-1, TGF- $\beta$, and ET- 1 regulate the amount of smooth muscle and collagen formation in cavernosal tissues. At higher levels of tissue hypoxia, collagen increased along with the instances of corporal fibrosis and smooth muscle apoptosis. This results in a shift in the smooth muscle content to collagen ratio in favor of collagen, leading to a dysfunctional penis and failure of veno-occlusion.

The persistent lack of erections after neuropraxia can itself set up an avalanche of harmful processes that can negatively affect EF. Wang summarized the mechanism of how chronic ED promotes the hypoxia of corporeal bodies. ${ }^{[12]}$ The ligation of the accessory internal pudendal arteries, in combination with neuropraxia, leads to hypoxia and lack of nocturnal erections. This later induces cavernosal fibrosis and transformation of the trabecular smooth muscle through collagen, which itself leads to the loss of the veno-occlusive mechanism necessary to maintain erections. The combination of nerve damage along with decreased arterial inflow may exacerbate hypoxia, ultimately resulting in apoptosis. ${ }^{[12]}$

After understanding the processes that promote ED after RP, multiple research studies have focused on evaluating ways to increase oxygen delivery to cavernosal bodies, decrease tissue fibrosis and apoptosis, and consequently improve EF. The role of penile rehabilitation is to maintain tissue oxygenation while preventing tissue fibrosis until the cavernosal nerves recover from neuropraxia with the goal to achieve spontaneous unassisted tumescence.

\section{Clinical trials and basic scientific evidence regarding penile rehabilitation}

Multiple studies have been conducted to investigate the roles of phosphodiesterase-5 inhibitors (PDE5i) and non-oral therapies in post-RP patients, and some studies have reported higher International Index of Erectile Function (IIEF) scores and spontaneous erection rates. ${ }^{[18-22]}$ Most of these studies had limitations that included the lack of a placebo group and randomization, suboptimal duration of medication usage, and significant patient dropout rate, which may call into question the statistical power of such studies. Unfortunately, most well-designed trials with adequate power and statistical validity have not shown any meaningful improvement in IIEF scores and recovery of spontaneous erections to the patient's preoperative state. ${ }^{[23-26]}$

\section{Evidence against penile rehabilitation}

Randomized controlled trials and a recent meta-analysis have established the consensus that daily PDE5i administration does not improve the recovery of spontaneous erections. ${ }^{[21-25]}$ The first randomized and placebo-controlled trials that assessed the clinical effects of oral PDE5i after RP were conducted by Padma-Nathan et al. ${ }^{[21]}$ Their study randomized 125 patients after nerve-sparing RP to sildenafil (50 or $100 \mathrm{mg}$ ) or placebo nightly for a total of 9 months. Out of the 125 patients in the trial, only 76 completed the washout evaluation period of 8 weeks after treatment. After the post-washout period, only 1 (4\%) out of 25 patients in the placebo arm had adequate EF vs. 14 (27\%) out of 51 patients in the combined sildenafil $50 \mathrm{mg}$ and $100 \mathrm{mg}$ groups. Although the authors suggested that nightly sildenafil doses benefited patients with post-prostatectomy ED, the study had a significant dropout rate, which potentially questions the statistical power of the study. The REINVENT penile rehabilitation after prostatectomy trial was a 628-patient multicenter, double-blind, placebo-controlled trial conducted by Montorsi et al. ${ }^{[23]}$, wherein patients with preoperative good erections were randomized into taking nightly vardenafil, on-demand vardenafil, or placebo for 9 months. The results of this trial did not support nightly vardenafil over on-demand 
dosing; further, after the washout period, no improvement in the IIEF scores was noted for either protocol when compared with the placebo group. With regard to other studies, limitations included a significant dropout rate $(31 \%-35 \%)$ in the study arms and no defined limit in drug usage was observed in the on-demand arm, therefore creating doubt that the two study arms truly represented different dosage patterns.

Pavlovich et al. ${ }^{[2]}$ found similar results when they randomized 100 men with good preoperative erections who had undergone nerve-sparing RP to receive either nightly sildenafil and ondemand placebo or on-demand sildenafil and nightly placebo starting the day after the surgery for a period of 12 months. A washout period of 1 month was allowed to assess spontaneous recovery at a follow-up of 13 months. The study also included a quantified nerve-sparing score (NSS) that assessed the quality of NVB preservation reported by surgeons. After the adjustment for potential confounding factors, the authors found no significant differences in EF between treatments at any single time point after RP. The only factor that was found to have a significant association with EF outcomes in all the longitudinal multivariable models was summary NSS. However, this study also had factors that weakened its findings. First, the authors did not create a pure placebo arm, fearing that patients would not want to be randomized to a placebo-only group. Ninety percent of the subjects were Caucasian, which hinder generalization to all populations. Moreover, the study period was 13 months, which is less than 18-24 months as recommended by other authors.

Another more recent RCT conducted by Montorsi et al. ${ }^{[25]}$ attempted to compare the efficacy of daily and on-demand tadalafil vs. placebo in improving unassisted EF and reducing the loss of penile length following nerve-sparing RP. The REACTT trial included 423 patients who were randomized into 9 months of treatment with tadalafil $5 \mathrm{mg}$ once daily, tadalafil $20 \mathrm{mg}$ on demand, or placebo followed by a 6-week washout period and 3 months open-label tadalafil once daily (all patients). The authors found that after the patients were treated for 9 months, reaching the target IIEF-EF $\geq 22$ was significantly different in the tadalafil once daily group as compared with the placebo group. However, after the drug-free washout period, the authors found no significant difference in EF between the groups with $20.9 \%, 16.9 \%$, and $19.1 \%$ patients reaching the target IIEF-EF scores in the tadalafil once daily, on-demand, and placebo groups, respectively. Regarding penile length, the authors reported that there was significantly less atrophy observed in the daily tadalafil group $(2.2 \mathrm{~mm})$ when compared with the other groups ( $7.9 \mathrm{~mm}$ on demand; $6.3 \mathrm{~mm}$ placebo) at 9 months of treatment. These data suggested that PDE5i may protect against structural changes in the cavernous body, and therefore, play a role in the preservation of cavernosal integrity after post-prostatectomy neuropraxia.
Previous trials have evaluated the use of PDE5i by relying on self-reported outcomes to determine the efficacy of therapy. To exclude the subjectivity of response bias, Kim et al. ${ }^{[26]}$ conducted a study to evaluate the effects of PDE5i using a more objective approach involving nocturnal rigidity (RigiScan ${ }^{\mathrm{TM}}$, Gotop Medical, Inc., St. Paul, MN, USA) in addition to the IIEF-EF score. After randomizing 97 patients into taking daily sildenafil with on-demand sildenafil or daily placebo with on-demand sildenafil, the group noted no significant difference in EF between the treatment groups based on both IIEF-EF domain scores and RigiScan data, suggesting that nightly sildenafil has no benefit over on-demand sildenafil.

Current literature data include clinical trials that assess the use of non-oral modalities such as intracavernosal injection (ICI) therapy, intraurethral alprostadil, and vacuum-erection devices (VED) as a part of penile rehabilitation. ${ }^{[22,27-31]}$ Similar to oral PDE5i, the use of such modalities have shown mixed results. A recent meta-analysis involved the screening of 11 randomized controlled trials and 5 case-control studies that assessed the use of PDE5i, VED, and ICI as a part of penile rehabilitation programs. The authors concluded that although these therapies can increase EF during the treatment phase, the current evidence does not support that penile rehabilitation can improve the recovery of spontaneous EF. ${ }^{[22]}$ Unfortunately, it is difficult to obtain a good objective judgment from the available evidence owing to limitations of the clinical trials. Most trials evaluated outcomes at one point (less than 12-13 months), which is suboptimal considering that EF has been suggested to take up to 4 years to fully recover. ${ }^{[15]}$ With these mixed results in clinical studies, one might wonder why many believe in penile rehabilitation. The answer lies in the evidence proven in animal and histological data.

\section{Evidence supporting penile rehabilitation}

Radical prostatectomy creates a series of histological alterations in cavernous tissues, which include a marked increase in collagen fibers along with a decrease in elasticity and smooth muscle cell fibers. Kovanecz et al. ${ }^{[32]}$ studied the temporal relationship in the corpora between the expression of inducible nitric oxide synthase, histological and biochemical changes, and the development of corporal veno-occlusive dysfunction after bilateral cavernosal nerve resection (BCNR). They compared histological penile tissue sections from rats that underwent either BCNR or sham operations; after treating the rats with sildenafil, their results revealed that sildenafil had a myogenic effect on tissues. ${ }^{[32]}$ These changes involving sildenafil were also observed when human subjects were involved. A penile biopsy performed during and 6 months after RP revealed no smooth muscle loss after 6 months in patients taking sildenafil $50 \mathrm{mg}$ and a significant increase in smooth muscle for those taking sildenafil $100 \mathrm{mg}$ $(\mathrm{p}<0.05){ }^{[33]}$ 
Other animal studies have shown multiple beneficial effects of PDE5i in nerve crush models. ${ }^{[12]}$ PDE5i has been shown to not only promote smooth muscle content but also ameliorate fibrotic degeneration normally seen in the corpora cavernosa after BCNR. This occurs through the modulation of the extracellular matrix and the gene expression of tissue growth factors, which protect against smooth muscle loss and fibrosis after RP. ${ }^{[34]}$ Other positive effects include a decrease in the oxidative stress, endothelial cell apoptosis, penile shaft collagen content, and hypoxia along with the prevention of venous leakage through cGMP-related mechanisms, both dependent and independent of the inducible nitric oxide synthase. ${ }^{[35,36]}$ All these mechanisms, in combination with the neuroprotective effects of PDE5i, have been proven to improve the overall EF. ${ }^{[12]}$

Another negative impact of RP on sexual function is penile shortening. Savoie et al. ${ }^{[37]}$ prospectively measured the penis of 124 men before and at 3 months after RP. Peyronie's disease and patients with a history of penile or urethral surgery were excluded. Their results showed that the size of the penis was smaller after RP with a significant difference for flaccid $(\mathrm{p}<0.001)$, stretched $(\mathrm{p}<0.001)$, pre-pubic fat pad $(\mathrm{p}=0.02)$, and penile circumference $(\mathrm{p}<0.01)$ measurements. Further, they observed that nerve sparing was not significant in relation to a change in the stretched penile length $(\mathrm{p}=0.609) .{ }^{[33]}$ For this reason, clinical researchers have explored the use of VED therapy to preserve penile size and found some benefits in patients using VED after RP. ${ }^{[26,27]}$ This led investigators to assess the impact of VED therapy on penile length and overall EF at a molecular level with BCNR in rats. Yuan et al. ${ }^{[38]}$ noted that VED therapy preserved EF through antihypoxic, antiapoptotic, and antifibrotic mechanisms. These findings were later confirmed with penile blood gas analysis, which showed an increase in cavernous blood oxygen saturation after VED therapy. ${ }^{[39]}$

In conclusion, currently, there is no standard treatment algorithm or established clinical guideline for EF recovery after $\mathrm{RP}$ because of controversial evidence in relation to penile rehabilitation. The perplexity of penile rehabilitation continues until better modalities become available. For now, it is clear that basic scientific studies show that penile rehabilitation programs have a theoretical benefit on EF. The majority of clinical studies involving PDE5i and non-oral therapies show that these are effectively tolerated and have been proven to improve early assisted function when compared with placebos. However, patients should be informed that current rehabilitation programs have not been proven to significantly improve unassisted erections. Although the current literature lacks irrefutable evidence regarding the effectiveness of penile rehabilitation modalities, this has not hindered urologists to include penile rehabilitation programs in their practices, and any rehabilitation is undeniably better than no action at all. ${ }^{[40]}$ It appears that patients with high pre-surgery sexual desire, confidence to get and maintain an erection, and pre-surgery intercourse satisfaction are the ones who will benefit the most from early rehabilitation after nervesparing RP. ${ }^{[26,41]}$ There still remains an opportunity for the development of bigger trials with sufficiently long-term follow-up to convince the scientific community that penile rehabilitation is inarguably effective.

Peer-review: Externally peer-reviewed.

Author Contributions: Concept - J.CH., B.E., A.K., R.W.; Design J.CH., B.E., A.K., R.W.; Supervision - J.CH., B.E., A.K., R.W.; Data Collection and/or Processing - J.CH., R.W.; Analysis and/or Interpretation - J.CH., B.E., A.K., R.W.; Literature Search - J.CH., B.E., A.K., R.W.; Writing Manuscript - J.CH.; Critical Review - J.CH., B.E., A.K., R.W.

Conflict of Interest: The authors have no conflicts of interest to declare.

Financial Disclosure: The authors declared that this study has received no financial support.

\section{References}

1. What are the key statistics about prostate cancer? American Cancer Society. Available from: https://www.cancer.org/cancer/ prostate-cancer/about/key-statistics.html. Last accessed on 2018 August 2.

2. Sanda MG, Dun RL, Michalski J, Sandler HM, Northouse L, Hembroff $\mathrm{L}$, et al. Quality of life and satisfaction with outcome among prostate -cancer survivors. N Engl J Med 2008;358:1250-61. [CrossRef]

3. Clavell-Hernandez J, Wang R. The controversy surrounding penile rehabilitation after radical prostatectomy. Transl Androl Urol 2017;6:2-11. [CrossRef]

4. Ficarra V, Cavalleri S, Novara G, Aragona M, Artibani W. Evidence from robot-assisted laparoscopic radical prostatectomy: a systematic review. Eur Urol 2007;51:45-56. [CrossRef]

5. Haglind E, Carlsson S, Stranne J, Wallerstedt A, Wilderäng U, Thorsteinsdottir $\mathrm{T}$, et al. Urinary incontinence and erectile dysfunction after robotic versus open radical prostatectomy: a prospective, controlled, nonrandomized trial. Eur Urol 2015;68:21625. [CrossRef]

6. Kilminster S, Müller S, Menon M, Joseph JV, Ralph DJ, Patel HR. Predicting erectile function outcome in men after radical prostatectomy for prostate cancer. BJU Int 2012;110:422-6. [CrossRef]

7. Salonia A, Castagna G, Capogrosso P, Castiglione F, Briganti A, Montorsi F. Prevention and management of post prostatectomy erectile dysfunction. Transl Androl Urol 2015;4:421-37.

8. Burnett AL, Aus G, Canby-Hagino ED, Cookson MS, D'Amico $\mathrm{AV}$, Dmochowski RR, et al. Erectile function outcome reporting after clinically localized prostate cancer treatment. J Urol 2007;178:597-601. [CrossRef] 
9. Mulhall JP. Defining and reporting erectile function outcomes after radical prostatectomy: challenges and misconceptions. J Urol 2009;181:462-71. [CrossRef]

10. Tal R, Alphs HH, Krebs P, Nelson CJ, Mulhall JP. Erectile function recovery rate after radical prostatectomy: a meta-analysis. $\mathrm{J}$ Sex Med 2009;9:2538-46. [CrossRef]

11. Hakky TS, Baumgarten AS, Parker J, Zheng Y, Kongnyuy M, Martinez $\mathrm{D}$, et al. Penile rehabilitation: the evolutionary concept in the management of erectile dysfunction. Curr Urol Rep 2014;15:393. [CrossRef]

12. Wang R. Penile rehabilitation after radical prostatectomy: where do we stand and where are we going? J Sex Med 2007;4:1085-97.

13. Walsh PC, Marschke P, Ricker D, Burnett AL. Patient reported urinary continence and sexual function after anatomical radical prostatectomy. Urology 2000;55:58-61. [CrossRef]

14. Mulhall JP, Slovick R, Hotaling J, Aviv N, Valenzuela R, Waters $\mathrm{WB}$, et al. Erectile dysfunction after radical prostatectomy: hemodynamic profiles and their correlation with the recovery of erectile function. J Urol 2002;167:1371-5. [CrossRef]

15. Mulhall J, Bivalacqua T, Becher E. Standard operating procedure for the preservation of erectile function outcomes after radical prostatectomy. J Sex Med 2013;10:195-203. [CrossRef]

16. Carrier S, Zvara P, Nunes L, Kour N, Rehman J, Lue T. Regeneration of nitric oxide synthase-containing nerves after cavernous nevre neurotomy in the rat. J Urol 1995;153:1722-7. [CrossRef]

17. Champion H, Abdel-Mageed A, Hellstrom W. Cavernous neurotomy causes hypoxia and fibrosis in rat corpus cavernosum. J Androl 2003;24:239-45. [CrossRef]

18. Mccullough AR, Levine LA, Padma-Nathan H. Return of nocturnal erections and erectile function after bilateral nerve-sparing radical prostatectomy in men treated nightly with sildenafil citrate: sub analysis of a longitudinal randomized double-blind placebocontrolled trial. J Sex Med 2008;5:476-84. [CrossRef]

19. Bannowsky A, Schulze C, Vander-Horst C, Hautmann S, Jünemann KP. Recovery of erectile function after nerve-sparing radical prostatectomy: improvement with nightly low-dose sildenafil. BJU Int 2008;101:1279-83. [CrossRef]

20. Pace G, Del Rosso A, Vicentini C. Penile rehabilitation therapy following radical prostatectomy. Disabil Rehabil 2010;32:1204-8. [CrossRef]

21. Padma-Nathan H, McCullough AR, Levine LA, Lipshultz LI, Siegel R, Montorsi F, et al. Randomized, double-blind, placebocontrolled study of postoperative nightly sildenafil citrate for the prevention of erectile dysfunction after bilateral nerve-sparing radical prostatectomy. Int J Impot Res 2008;20:479-86. [CrossRef]

22. Liu C, Lopez DS, Chen M, Wang R. Penile rehabilitation therapy following radical prostatectomy: a meta-analysis. J Sex Med 2017;14:1496-503. [CrossRef]

23. Montorsi F, Brock G, Lee J, Shapiro J, Van Poppel H, Graefen M, et al. Effect of nightly versus on-demand vardenafil on recovery of erectile function in men following bilateral nerve-sparing radical prostatectomy. Eur Urol 2008;54:924-31. [CrossRef]

24. Pavlovich CP, Levinson AW, Su LM, Mettee LZ, Feng Z, Bivalacqua TJ, et al. Nightly vs on-demand sildenafil for penile rehabilitation after minimally invasive nerve-sparing radical prostatectomy: results of a randomized double-blind trial with placebo. BJU Int 2013;112:844-51. [CrossRef]

25. Montorsi F, Brock G, Stolzenburg JU, Mulhall J, Moncada I, Patel HR, et al. Effects of tadalafil treatment on erectile function recovery following bilateral nerve-sparing radical prostatectomy: a randomized placebo-controlled study (REACTT). Eur Urol 2014;65:587-96. [CrossRef]

26. Kim DJ, Hawksworth DJ, Hurwitz LM, Cullen J, Rosner IL, Lue $\mathrm{TF}$, et al. A prospective, randomized, placebo-controlled trial of on-demand vs. nightly sildenafil citrate as assessed by Rigiscan and the international index of erectile function. Andrology 2016;4:27-32. [CrossRef]

27. Montorsi F, Guazzoni G, Strambi LF, Da Pozzo LF, Nava L, Barbieri L, et al. Recovery of spontaneous erectile function after nerve-sparing radical retropubic prostatectomy with and without early intracavernous injections of alprostadil: results of a prospective, randomized trial. J Urol 1997;158:1408-10. [CrossRef]

28. Mulhall J, Land S, Parker M, Waters WB, Flanigan RC. The use of an erectogenic pharmacotherapy regimen following radical prostatectomy improves recovery of spontaneous erectile function. J Sex Med 2005;2:532-40. [CrossRef]

29. McCullough AR, Hellstrom WG, Wang R, Lepor H, Wagner KR, Engel JD. Recovery of erectile function after nerve sparing radical prostatectomy and penile rehabilitation with nightly intraurethral alprostadil versus sildenafil citrate. J Urol 2010;183:2451-6. [CrossRef]

30. Kohler TS, Pedro R, Hendlin K, Utz W, Ugarte R, Reddy P, et al. A pilot study on the early use of the vacuum erection device after radical retropubic prostatectomy. BJU Int 2007;100:858-62. [CrossRef]

31. Raina R, Pahlajani G, Agarwal A, Jones S, Zippe C. Long-term potency after early use of a vacuum erection device following radical prostatectomy. BJU Int 2010;106:1719-22. [CrossRef]

32. Kovanecz I, Rambhatia A, Ferrini M, Vernet D, Sanchez S, Rajfer $\mathrm{J}$, et al. Long-term continuous sildenafil treatment ameliorates corporal veno-occlusive dysfunction (CVOD) induced by cavernosal nerve resection in rats. Int J Impot Res 2008;20:202-12. [CrossRef]

33. Schwartz EJ, Wong P, Graydon RJ. Sildenafil preserves intracorporeal smooth muscle after radical retropubic prostatectomy. J Urol 2004;171:771-4. [CrossRef]

34. Sirad F, Hlaing S, Kovanecz I, Artaza JN, Garcia LA, Rajfer J, et al. Sildenafil promotes smooth muscle preservation and ameliorates fibrosis through modulation of extracellular matrix and tissue growth factor gene expression after bilateral cavernosal nerve resection in the rat. J Sex Med 2011;8:1046-60. [CrossRef]

35. Kovanecz I, Rambhatia A, Ferrini MG, Vernet D, Sanchez S, Rajfer J, et al. Chronic daily tadalafil prevents the corporal fibrosis and veno-occlusive dysfunction that occurs after cavernosal nerve resection. BJU Int 2008;101:203-10.

36. Mulhall JP, Müller A, Donohue JF, Mullerad M, Kobylarz K, Paduch DA, et al. The functional and structural consequences of 
cavernous nerve injury are ameliorated by sildenafil citrate. J Sex Med 2008;5:1126-36. [CrossRef]

37. Savoie M, Kim SS, Soloway MS. A prospective study measuring penile length in men treated with radical prostatectomy for prostate cancer. J Urol 2003;169:1462-4. [CrossRef]

38. Yuan J, Lin H, Li P, Zhang R, Luo A, Berardinelli F, et al. Molecular mechanisms of vacuum therapy in penile rehabilitation: a novel animal study. Eur Urol 2010;58:773-80. [CrossRef]

39. Lin HC, Yang WL, Zhang JL, Dai YT, Wang R. Penile rehabilitation with a vacuum erectile device in an animal model is related to an antihypoxic mechanism: blood gas evidence. Asian J Androl 2014;15:387-90. [CrossRef]

40. Tal R, Teloken P, Mulhall JP. Erectile function rehabilitation after radical prostatectomy: practice patterns among AUA members. J Sex Med 2011;8:2370-6. [CrossRef]

41. Mulhall JP, Brock G, Oelke M, Fode M, Probst KA, Henneges $\mathrm{C}$, et al. Effects of Tadalafil once-daily or on-demand vs placebo on return to baseline erectile function after bilateral nerve-sparing radical prostatectomy-results from a randomized controlled trial (REACTT). J Sex Med 2016;13:679-83. [CrossRef] 